\title{
El terror digital y sus relaciones con el fuera de campo
}

\author{
Digital horror and out-of-field
}

CHRISTIAN CHECA BAÑUZ*

\begin{abstract}
Resumen: Cuando una nueva tecnología surge, con ella surgen también ciertos efectos de extrañamiento, que quedan asimilados a la representación a medida que el espectador se acostumbra a ellos. Estos efectos, no obstante, no son cancelados tanto como silenciados en función de ciertas estrategias. Puede trazarse así su desarrollo desde los cuerpos monstruosos del cine de terror hollywoodiense hasta la no-clausura de la imagen digital contemporánea, pasando por la rarificación del espacio fílmico en el cine de Jacques Tourneur.

Palabras clave: Extrañamiento, cuerpo monstruoso, espacio rarificado, inimaginable, no-clausura, imagen digital.
\end{abstract}

\begin{abstract}
When changes in technology appear, certain strangeness effects appear with them, which do not vanish until they become familiar to the spectator. These effects o not disappear, instead they are concealed according to different commercial strategies. Therefore, it is possible to trace their development throughout the years from the monstrous bodies of the Hollywood terror genre, to the rarefaction of cinematic space in Jacques Tourneur's films, and the openness of the digital contemporary image.

Key words: Strangeness, monstrous body, rarefied space, unimaginable, openness, digital image.
\end{abstract}

\section{Cuerpos extraños}

En su estudio sobre el nacimiento del terror como género en Hollywood, Uncanny bodies, Robert Spadoni argumentaba que no era casual (sino más bien "causal") que el ciclo de películas de monstruos de la Universal que da comienzo con el Drácula de Tod Browning y el Frankenstein de James Whale, ambas de 1931, tuviese lugar al final de ese periodo de transición de la imagen cinematográfica que comienza en 1927 cuando los cuerpos mudos de repente empezaron a hablar.

La llegada del sonido sincrónico supone para el cine su primera gran revolución tecnológica. Teóricamente esta revolución siempre ha sido considerada como una conquista del realismo en la imagen. Sin embargo, este "incremento realista" no se percibió como tal hasta un tiempo después, los primeros visionados vinieron inevitablemente acompañados por un efecto contrario de extrañamiento. Súbitamente, con la aparición de las talkies, el

Fecha de recepción: 10/06/2016. Fecha de aceptación: 27/07/2016.

* Profesor en la Escuela Superior de Cine y Audiovisuales de Cataluña (ESCAC). Áreas de investigación: Nuevas tendencias del cine contemporáneo/Cine y Pensamiento. christiancheca@ hotmail.com 
espectador de cine, habituado como ya estaba a unos cuerpos que hablaban sólo a través del gesto, de la mímica, se vio enfrentado a unos cuerpos "naturalizados" en virtud de esa dimensión interior que sólo la voz puede reflejar: los cuerpos, de repente, adquirían cierto volumen.

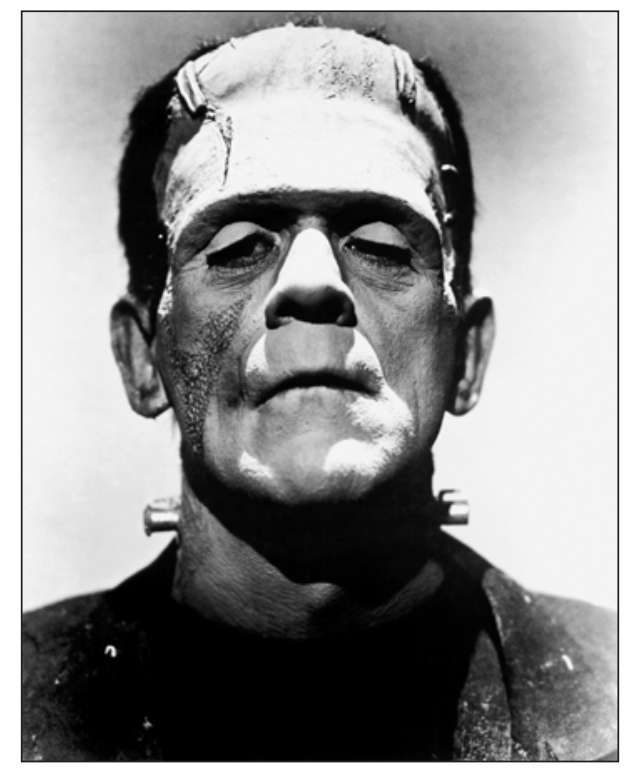

Sin embargo, la imagen seguía teniendo las mismas cualidades de superficie y cromaticidad. Así, lo que se produjo fue un efecto que puede ser generalizado a todo advenimiento de una nueva tecnología: no importa si ésta apunta hacia un mayor realismo, con ella lo familiar se vuelve inaudito, extraño o, incluso, siniestro. Unheimlich, que diría Freud.

Estos nuevos cuerpos parlantes, a los que habría que añadir las inevitables deficiencias de las que adolecían los primeros sistemas de sonido en lo que respecta a la sincronía y a la calidad auditiva, generó lo que Spadoni (siguiendo a Yuri Tsivian en su estudio acerca de los orígenes del cine soviético') llama "espectador sensitivo al medio", es decir, un espectador que ya no disfruta pasivamente de imágenes sino que atiende a la propia materialidad de las imágenes, al proceso mismo de producción que les da forma, incrementando su capacidad reflexiva en virtud de una nueva tecnología. Ahora bien, una vez los cambios provocados por la tecnología son asimilados y sus métodos perfeccionados, este espectador especialmente sensitivo vuelve a habituarse a cuerpos ahora ya plenamente parlantes. Hasta que no se culmina ese periodo de adaptación, breve pero relevante, el espectador no se reencuentra con una imagen más fiel o más realista de sí mismo.

1 TSIVIAN, Y., Early Cinema in Russia and Its Cultural Reception, London, Routledge, 1994. 
Sin embargo, este incremento de realismo hace patente algo de lo que previamente el espectador no era consciente: a la imagen aún le faltan más dimensiones. Es decir, de repente la imagen en blanco y negro muestra ciertas carencias a las que el espectador del mudo no había atendido: un cuerpo plano en blanco y negro que hable resulta incongruente, a este cuerpo que ahora habla aún le faltan rasgos como el color, el volumen, etc. En palabras de Spadoni:

A critic commented the previous year that «the moment a character begins to speak from the screen his bodily unreality becomes marked-at least until one becomes accustomed to it.» ${ }^{2}$ Such feelings of unreality contributed to a general sense that more sensory information needed to be added to Hollywood films. A commentator in 1930 wrote that «the demand for color photography ... increased to an almost unbelievable extent after the advent of sound and is steadily increasing. No doubt the incongruity of black and white images speaking lines and singing songs like living beings created a demand for a greater illusion of reality. This color photography helps to supply.» ${ }^{34}$ As Claudia Gorbman writes, «the recorded voice fleshed out the human body on the screen.»5 Also, however, the voice initially drained this body of its color and vitality. Such a body, at once lifeless and three-dimensional, might have born a resemblance to a living human corpse. ${ }^{6}$

Es decir, el sonoro viene a ser algo así como un punto de no retorno en un proceso incesante de normalización de los cuerpos que encuentra hoy su máxima expresión en las imágenes tridimensionales y en la realidad virtual. Sin embargo, cabe preguntarse si este proceso tendrá alguna vez un fin, si las ambiciones del realismo llegarán a colmarse y si alguna vez la herida abierta por el sonoro llegará a cicatrizar o, por el contrario, si permanecerá siempre abierta en virtud de una extrañeza permanente de los cuerpos audiovisuales imposible de aplacar por completo.

Pero antes de seguir, conviene recordar que uno de los objetivos de Spadoni es caracterizar, no el nacimiento del cine de terror, que puede ser localizado mucho antes de la década de los 30 (en la corriente expresionista alemana, por ejemplo; o en el cine nórdico), sino el nacimiento del terror como "género" dentro de la producción sistemática de Hollywood. ¿Por qué tiene esto un interés especial? Porque el nacimiento del género de terror en Hollywood pone en evidencia ciertos mecanismos típicos de la industria cinematográfica (mecanismos “esquizoides", que dirían los Deleuze y Guattari de Capitalismo y esquizofrenia ${ }^{7}$ ). Por un lado, este efecto de extrañamiento es algo que debe ser aplacado, a fin de que el espectador no se sienta incómodo y deje de ir al cine. Nicholas Royle, en su libro titulado justamente

2 SELDES, G., "The movies commit suicide”, en Harper's, Nueva York, noviembre de 1928, p. 710.

3 SEITZ, J., Cinematographic Annual 1930, Nueva York, Arno Press, 1972, p. 17.

4 SPADONI, R., Uncanny bodies, the coming of sound film and the origins of the horror genre, Berkeley, University of California Press, 2007, p. 23.

5 GORBMAN, C., Unheard Melodies: Narrative Film Music, Bloomington, Indiana University Press, 1987, p. 41.

6 SPADONI, R., op. cit.p. 26.

7 DELEUZE, G., GUATTARI, F., El Anti-Edipo, Capitalismo y esquizofrenia I, Barcelona, Paidós, 1985, traducción de Francisco Monge. DELEUZE, Gilles, GUATTARI, Félix, Mil mesetas, Capitalismo y esquizofrenia II, Valencia, Pre-textos, 2004, traducción de José Vázquez Pérez. 
The uncanny -de nuevo "lo siniestro", lo unheimlich-, escribe: "the entire [film] 'industry'

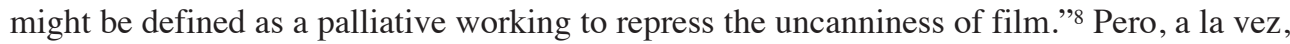
está también en la naturaleza de la industria capitalizar en la medida de lo posible todo efecto de novedad, incluso aquel que pueda atentar contra su propia integridad.

Uno de sus mecanismos clásicos para reprimir esta extrañeza es cercarla en un contexto concreto, ponerle nombres, darle formas. Puede interpretarse así el nacimiento del género de terror en Estados Unidos como fruto de la confluencia de estos dos fenómenos. Por un lado la conciencia, por parte del espectador, de la extrañeza de los cuerpos que el cine muestra. Y por otro, la capitalización que la industria hace de esos cuerpos extraños bajo el efecto de domesticación del género: combatir la extrañeza congénita de los cuerpos cinematográficos mediante cuerpos cuya extrañeza ha sido exagerada. Extrañeza que puede que siga activa, aunque silenciada, en la época contemporánea.

\section{Espacios extraños}

Este exceso de extrañeza depositado sobre los cuerpos de los monstruos de la Universal sufre un desplazamiento interesante en la continuación más inmediata del género bajo las siglas de la productora RKO, muy especialmente -o casi de manera exclusiva, como ha mostrado el doctor Santiago Fillol en su tesis doctoral-, en las películas dirigidas por Jacques Tourneur. En ellas el cuerpo extravagante del monstruo desaparece en favor de otro elemento que adquiere una función y una relevancia inusitadas antes: el fuera de campo. Dice Fillol que, excepto en contadas excepciones, en el cine de los años 30 "la amenaza encubierta en el margen de la imagen es perfectamente explicada, y causalizada, por la narración. [...] El fuera de campo no es un recurso privilegiado para acoger la presencia inquietante: cuando el decoro no justifica su empleo, éste ni siquiera es utilizado." ${ }^{\circ}$

Tourneur es probablemente el único cineasta que ha trabajado desde el clasicismo el fuera de campo como espacio de lo indefinido, de una otredad impensable [...]. [Tourneur] se enfrenta a las imposibilidades del lenguaje para asir lo otro, sin abandonar la narración por la forma, pero sin tematizar tampoco la forma desde la narración. La continuidad en la suspensión es, en definitiva, una obstinación por seguir narrando aunque la narración ya no alcance para tapar todos los huecos abiertos por un otro que golpea a la puerta desde el fondo de la imagen..$^{10}$

En Tourneur ya no hay monstruos pero el efecto de extrañamiento o lo siniestro no desaparece con ellos, sino que aparece justamente en su ausencia, es decir, en el espacio vacío donde su cuerpo debería aparecer. Es el espacio mismo el que se vuelve aquí siniestro.

8 ROYLE, N., The Uncanny. New York, Routledge, 2003, p. 75.

9 FILLOL, S., Manifestaciones de una lejanía (por cercana que pueda estar), pp. 75-76. (http://hdl.handle. net/10803/31899; consultado el 25/02/2015)

10 FILLOL, S., op. cit. p. 79. 


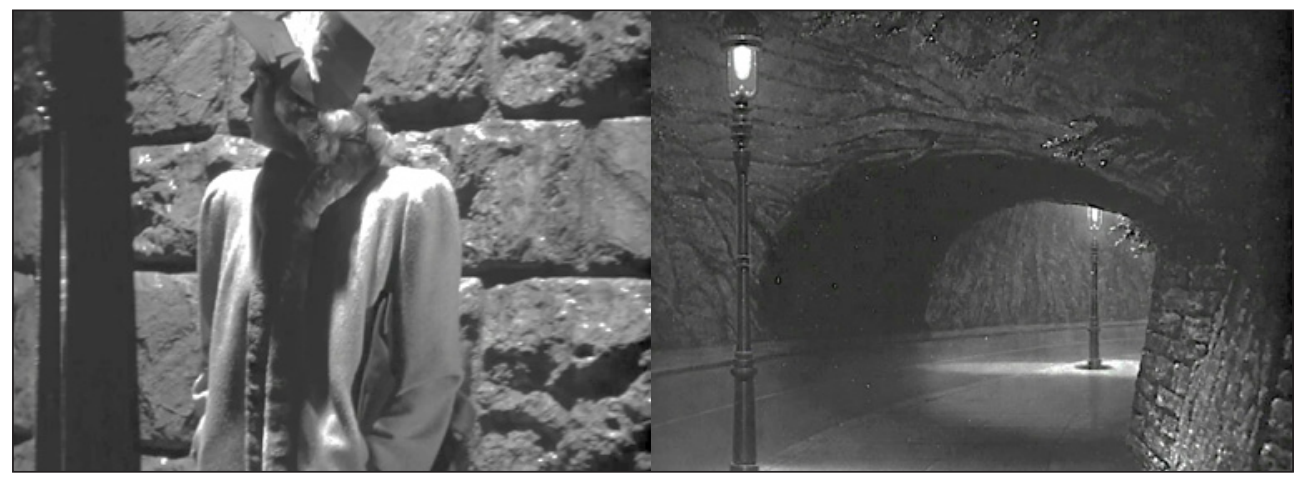

Por ejemplo, en la célebre escena de la persecución callejera de La mujer pantera, Alice se siente amenazada por Irena, que la sigue de cerca, y se gira para descubrir el campo a sus espaldas. ¿Qué ve Alice? Nada. Pero una "nada” que no es totalmente la nada, pues hay elementos dentro del encuadre, sino, más que una nada, una ausencia: la ausencia de Irena en su forma humana que hemos visto planos atrás y, por lo tanto, la presencia de su forma felina agazapada en algún lugar oscuro, amenazante.

Además de esta ausencia en el campo, Tourneur hace otro uso un poco diferente del fuera de campo.

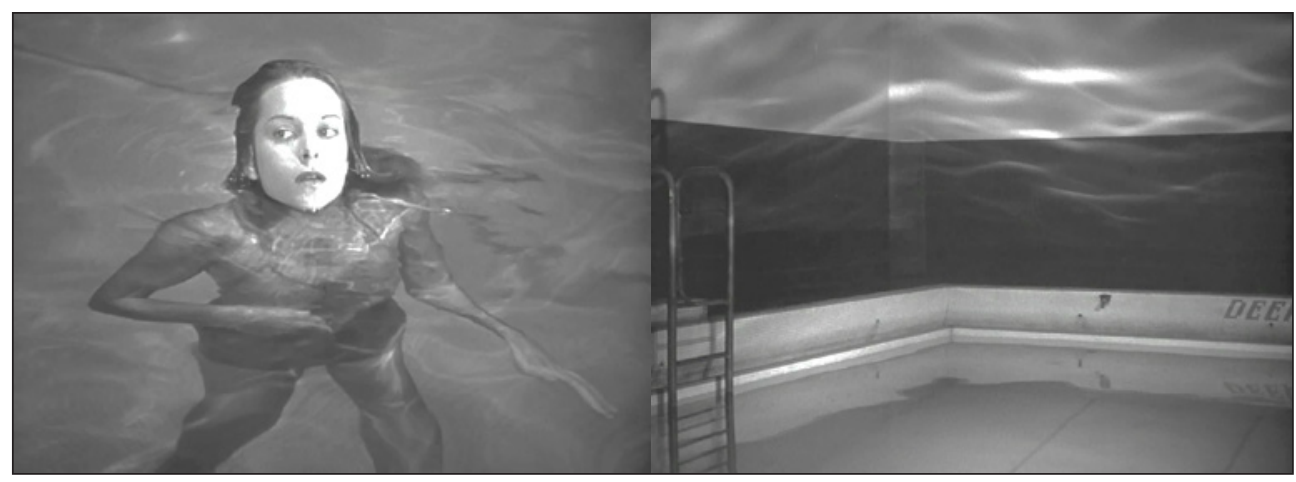

En la igualmente célebre escena de la piscina observamos cómo Irena se asocia a regiones negras del encuadre, a la oscuridad. Su presencia cercana - tan "cercana" como que puede estar justamente en el interior del campo sin ser vista- viene determinada por áreas de oscuridad que señalan su amenaza, áreas que abren en el interior del encuadre regiones imprecisas que se identifican con el propio personaje. Alice, flotando en la piscina, no está siendo simplemente acosada por un felino, está, de hecho, totalmente rodeada por la presencia-ausencia de Irena gracias a un área negruzca pintada en las paredes de la habitación. Se genera con ello un fuera de campo en el campo, se abre una fisura extraña en el interior de la representación misma. Abriendo de nuevo en el contexto de lo familiar (el cine de género hollywoodiense) un lugar para la extrañeza. 
Noël Burch se refería al fuera de campo en Praxis del cine $e^{l l}$ como imaginario o concreto. A grandes rasgos, diremos con Burch que un fuera de campo es concreto cuando se conoce, se materializa en imagen, y que un fuera de campo es imaginario cuando únicamente se evoca sin llegar a materializarse en el plano. Lo más habitual es que un espacio off imaginario termine convirtiéndose en concreto: cuando un movimiento de la cámara o un cambio de plano revela ese espacio que hasta el momento quedaba fuera de campo. Sin embargo, el uso que hace Tourneur del fuera de campo en La mujer pantera cae totalmente del lado de lo imaginario, ya que la pantera en la escena de la persecución y en la escena de la piscina nunca llega a visualizarse (tan sólo percibimos su ausencia).

\section{Monstruos digitales y miradas sin respuesta}

En nuestra época las posibilidades de manipulación de la imagen y la amplia gama de efectos visuales que ofrece la tecnología digital amplían el campo de representación de lo monstruoso hasta unos niveles de realismo sin precedentes. Los vemos por doquier: zombies, vampiros, brujas y demás fauna genérica tratan de propagar el terror, cada uno más sangriento, más hipertrofiado, más podrido que el anterior. En lo que respecta a estados alterados del cuerpo, ya nada ha de sugerirse porque todo puede ser mostrado mediante la digitalización. Esta proliferación monstruosa - de la cual hallamos también variaciones intergenéricas en las que vampiros parecen superhéroes y ejércitos de zombies se disponen en tropel a conquistar el mundo- provoca que las "alteraciones", aquellos cuerpos que un día fueron siniestros y extraños, se estén convirtiendo en estados normales, imágenes convencionales que podrían llevarnos a pensar que evolucionamos hacia un mundo audiovisual en el que el fuera de campo se reduce en términos absolutos, o incluso desaparece, ya que todo lo imaginable puede ser mostrado y eso ensancha hasta el infinito el conjunto de imágenes susceptibles de entrar en campo.

Ahora bien, pareja a esta lúdica hipertrofia monstruosa hallamos otra tendencia muy distinta dentro de la imagen digital cuyos recursos están igualmente arraigados en los nuevos métodos y gestiones de la producción derivados de la cultura electrónica. En lugar de basar su discurso en hacer concreto todo lo imaginable, películas como Monstruoso (Cloverfield, Matt Reeves, 2008) o, muy especialmente, El proyecto de la bruja de Blair (The Blair witch project, Daniel Myrick y Eduardo Sánchez, 1999) se nutren de imágenes parciales que explotan sistemáticamente el fuera de campo, todo en función del uso de dispositivos de grabación digital.

La película de Myrick y Sánchez supone un ejemplo perfecto de cómo generar un efecto de extrañamiento en virtud de ciertas características clave de una nueva tecnología. En El proyecto de la bruja de Blair nunca llegamos a ver a la bruja ni tampoco la mayoría de la diégesis en la que tiene lugar la acción. Incluso en ocasiones la imagen misma desaparece, ya que a veces sólo vemos una pantalla negra y escuchamos ruidos de precedencia indefinida.

11 BURCH, N., Praxis del cine, Madrid, Fundamentos, traducción de Ramón Font, 2008. 


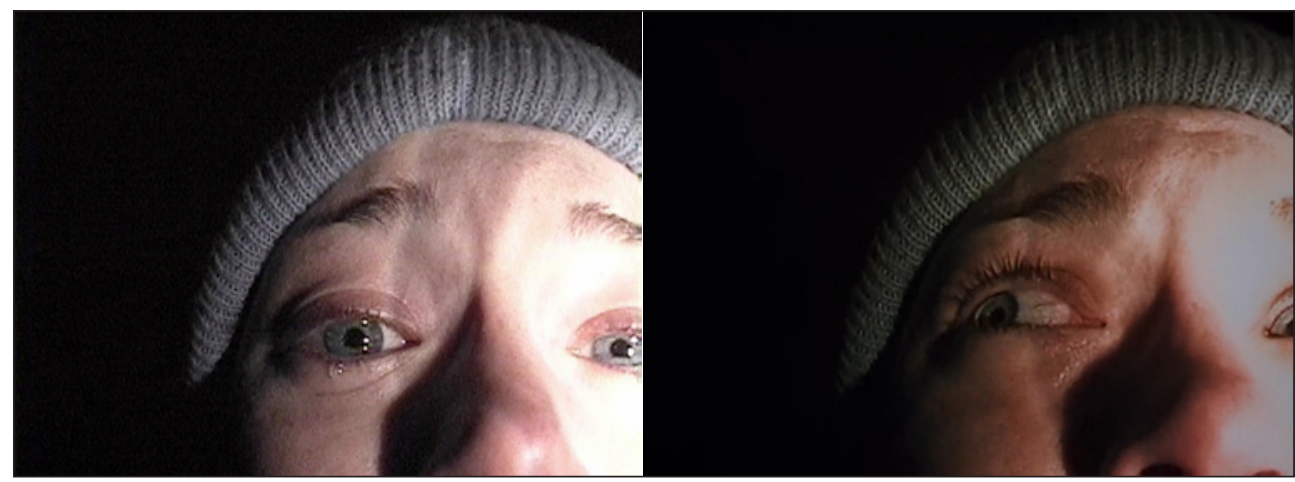

Es decir, lo que se ha vuelto extraño no son tanto ya el cuerpo ni el espacio, sino algo en la imagen misma. En la escena en la que la protagonista se despide de su propia familia y pide disculpas a las familias de sus compañeros, de estar mirándose en la cámara como en un espejo, la chica dirige su atención hacia más allá del encuadre guiada por un ruido que nosotros no hemos oído. Y entonces ese fuera de campo se torna aterrador, no porque en nuestra mente se forme la imagen terrorífica de un bosque encantado, de una bruja, o un monstruo, ya que todos hemos visto ya demasiadas brujas y monstruos, sino -y esto es lo "ejemplar" de este ejemplo- porque jamás viene un contracampo a suturar la representación.

Mientras que en Tourneur los espacios se volvieron extraños en virtud de ciertas ausencias, en El proyecto de la bruja de Blair no hay siquiera un espacio de ausencia, sino un contracampo especular de dicho espacio: la mirada no respondida de la protagonista. Como si el fuera de campo se plegara sobre sí, esa imagen es además doblemente reflejante, pues, al mirarle directamente a él, la chica devuelve al espectador la imagen especular de su propio terror. Así, en la no-clausura del espacio diegético se establece un circuito psíquico entre el espectador y un vacío vertiginoso con el rostro de la protagonista como catalizador.

En Tourneur, aunque el fuera de campo mostrara tanta insistencia en el campo, siempre encontraba un contracampo con el que clausurar la representación. En La mujer pantera Alice mira tras de sí. Vemos el plano de una calle, una farola y un puente, y acto seguido se nos devuelve, por corte, de nuevo al plano medio de Alice mirando hacia atrás. Mirada y contracampo suturados en un montaje orgánico. En cambio, lo que resulta traumático en la película de Myrick y Sánchez no es tanto la bruja (el cuerpo monstruoso), tampoco un espacio rarificado por una ausencia, sino la ausencia misma de una visión global. Eso es lo que resulta traumático: las brujas y los monstruos ya no dan miedo, el colapso del sistema representativo es lo que nos hace perder pie, la presencia de un agujero negro allí donde el relato debía clausurarse.

Así, los nuevos efectos de extrañamiento generados por el digital tienen que ver, no ya tanto con cuerpos monstruosos o con seres imaginables que cobran vida en la pantalla, sino con que el cuerpo mismo del cine, su efecto cohesivo y estructural, se está viendo desmembrado a causa de la revolución tecnológica en la que el cine se ve inmerso. En el ejemplo concreto de El proyecto de la bruja de Blair, esta revolución adquiere la forma de esas pequeñas cámaras de vídeo cuyos usos extendidos no se orientan a la creación de mundos 
cohesionados, de diégesis homogéneas, sino hacia la captación heterogénea de fragmentos de vida. De hecho, el trayecto que va de la cámara al hombro de la época analógica a la cámara en mano de la era digital está caracterizado por la posibilidad de la auto-grabación: la pequeña cámara en mano puede volverse sobre el rostro de quien la sostiene. Con ello, la imagen se vuelve auto-imagen y asume más si cabe la fragmentación constitutiva de un punto de vista que no puede abarcar la totalidad.

Esta condición de las imágenes nos remite directamente al modo en que los hombres y las mujeres de hoy interpretan y experimentan el mundo que les rodea. Nuestro mundo ha perdido el relato como modelo interpretativo para abrazar el hipertexto. Es decir, ha dejado de pensar la deriva del tiempo como una historia lineal para experimentar la unión modulable, variable y precaria de espacios y tiempos heterogéneos, fragmentados y desiguales.

\section{Lo inimaginable}

Estos intervalos abiertos por la tecnología allí donde debería haber efectos de sutura, nos llevan a pensar la posibilidad de un fuera de campo que ya no es concreto o imaginario, sino que casi podríamos llamar inimaginable. Un fuera de campo que ya no es tanto imagen como no-imagen, pero que no es en absoluto una nada ya que insiste en el plano como una latencia ineludible. Lo inimaginable es la materia oscura de la que se nutre el fuera de campo imaginario pero que retiene un núcleo inagotable por ser esencialmente no audiovisual. Es justamente ese efecto terrorífico de no-clausura que, en cierto modo, comienza en Tourneur, pero que, como dice Santiago Fillol "era de tal magnitud que sólo pudo ser asimilado como tal en posteriores manifestaciones de la historia del cine."”2 Fillol está pensando aquí en David Lynch, cineasta de ecos tourneurianos que va más allá de Tourneur gracias a la exploración de las posibilidades digitales de la imagen.

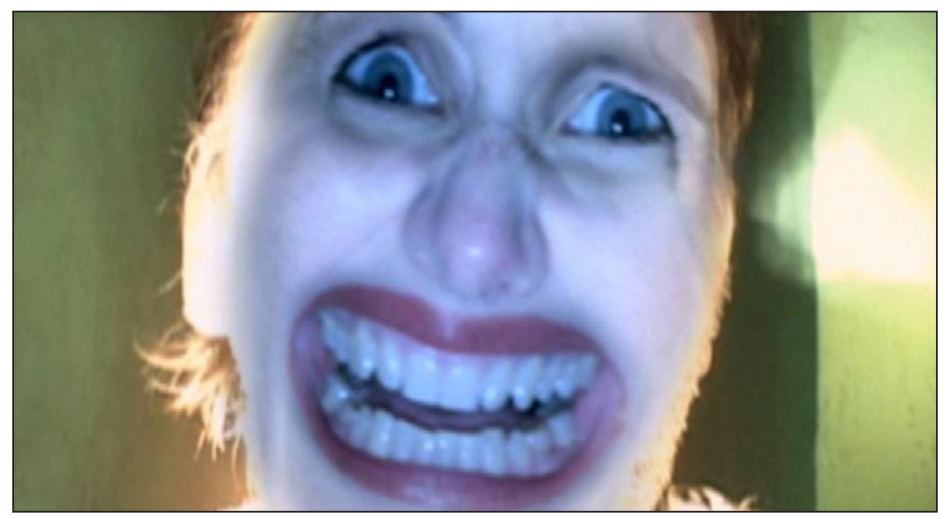

Los monstruos pueden acabar resultando tiernos e incluso aliados de los hombres. Cuando algo cae de lo imaginario a lo concreto ya toda domesticación es posible. Sin embargo, lo realmente terrorífico es que algo caiga del lado de lo inimaginable, que en el

12 FILLOL, S., op. cit. pp. 80-81. 
fuera de campo se abra una brecha inimaginable, o, yendo más allá, que lo inimaginable se apodere de la imagen, que en la imagen misma aparezca una pequeña brecha de fuera de campo, una herida imposible de cicatrizar, como en Inland Empire (David Lynch, 2006).

Algo así aparecía ya en la escena de la piscina de La mujer pantera, lo hemos dicho: un fuera de campo en el campo. Ahora bien, ese fuera de campo remite a algo que podemos imaginar: una pantera. En cambio, Inland Empire está por entero construida bajo la insistencia en el campo de lo inimaginable. De ahí su débil sutura, de ahí que todo el entorno diegético muestre fisuras. Como si una fuerza extraña hubiese ganado la partida a los vínculos del montaje y los planos comenzasen a girar unos alrededor de otros, desafiando la sucesión cronológica y empezando a resonar los posteriores en los anteriores, y viceversa. La película deja entonces de funcionar en serie y se disgrega rizomáticamente como un hipertexto.

Inland Empire lleva al espectador, no tanto hacia pensamientos concretos, según una estructura lógica, sino hacia la paradoja, hacia el toque del sinsentido. Incluso el punto de anclaje más firme que el espectador tiene en la narración, el personaje, se "abre", se disgrega. Es como si el rostro de la protagonista, que en El proyecto de la bruja de Blair actuaba de catalizador especular, aquí genere un cortocircuito adicional. El rostro humano, que durante más de un siglo ha sido el foco de la figuración fílmica, nos aparece entonces desgarrado, quebrado, abierto de par en par para mostrar su reverso delirante. Es como si Lynch nos dijera: "he aquí vuestra imagen arquetípica, la he abierto para que la podáis ver, pero lo que hay detrás es lo invisible, lo irrepresentable, lo inimaginable." Porque lo imposible en Inland Empire es formarse una imagen, formar la imagen cohesionada que nos haga recobrar la percepción global, es decir, la referencia de los primeros planos, de los fragmentos, a un plano de conjunto con sentido.

Para Fillol lo que encontraríamos en Inland Empire es algo así como un desencanto por las formas del cine:

Sus cortes raudos y brutos, la exagerada frontalidad de algunos de sus planos, los rostros desgranados, desfigurados, de los personajes; su dificultad para dar con una mesura estable en las distancias entre los seres y el espacio, la utilización de un raccord rudimentario que deriva en una continuidad a trompicones, dejan reconocer en su puesta en escena la presencia de cierto arcaísmo. Y esta experiencia se acerca más a una esforzada vuelta a cero figurativa, ejercida desde el cementerio de chatarra que la historia del cine ha dejado tras su siglo, que a un supuesto y elevado grado de su desarrollo formal. ${ }^{13}$

Todas las estrategias de "des-naturalización" de la imagen o escape de la figuración de Lynch tienen también como punto de partida su fascinación por las pequeñas cámaras digitales y el retorno de una cierta materialidad del medio. En una entrevista para Cahiers du cinéma dice:

13 FILLOL, S., op. cit. pp. 189-90. 
En el registro de video que utilizo en Inland, la calidad es felizmente horrible, y yo amo que sea así. Me recuerda al $35 \mathrm{~mm}$ de los primeros tiempos del cine, cuando no había tanta información en la imagen o en la emulsión. ${ }^{14}$

Es decir, lo que ha traído consigo la tecnología digital no es sólo un "espectador sensible al medio", como sucedió con el advenimiento del sonoro, sino también un tipo del cineasta especialmente sensible a las posibilidades no figurativas de una nueva tecnología. Lynch parece decidido a explorar así no ya los límites terroríficos de cuerpos monstruosos, ni los límites ausentes de espacios vacíos, sino los límites vertiginosos de una imagen no clausurada.

Y si a Lynch la imagen digital le recuerda "a los primeros tiempos del cine", esta "noclausura" es, por otro lado, una de las características que Noël Burch dio del cine previo al modelo institucional.

Si consideramos la clausura institucional como algo más que una autosuficiencia narrativa, que una determinada forma de clausurar el relato; si [...] la consideramos como la suma de todos los sistemas significantes que centran el sujeto y que condicionan el pleno efecto diegético, incluyendo el marco mismo de la proyección; entonces sí, el sistema primitivo, en su conjunto, no está clausurado. ${ }^{15}$

No-clausura que para Santiago Fillol no revela tanto "un mecanismo formal, sino más bien, una vivencia de lo abierto ante las imágenes, donde la fuga y la suspensión del sentido eran parte activa de su figuración y recepción." 16 . Es decir, la vivencia propia del cine de los orígenes es la de un espectador para el cual toda imagen tenía los visos de lo nuevo, de lo inimaginable, de lo inexplorado.

Así pues, si esta no-clausura perteneció al cine en sus orígenes y sólo desapareció una vez la carga institucional impuso ciertas condiciones de relato, ¿por qué no pensar que la no-clausura, lo inimaginable, es connatural al cine? Quizá convendría no pensar en Inland Empire como un retorno a un cierto primitivismo, sino como una toma de conciencia acerca de algo que siempre ha estado ahí, pero ha sido silenciado. Lo interesante sería entonces ver cómo esta función inimaginable del fuera de campo que tan arraigada parece en el cine de terror podría extrapolarse a otros géneros o a otras maneras de tratar la imagen (pienso quizá en los pillow-shots de Ozu, cuya cercanía con el terror parece inverosímil). Incluso, yendo más allá, lo interesante sería preguntarse si este inimaginable no está de algún modo presente en toda imagen, si toda imagen no tiene, por así decir, una anti-imagen, un fuera de campo absoluto detrás o incluso dentro de ella. Sería preguntarse si esta función inimaginable del fuera de campo no es sino la expresión verdaderamente "artística" del horror; si lo artístico no es, justamente, situar al espectador ante el cuerpo extraño, ante el espacio raríficado, ante la imagen no-clausurada que ya no devuelve un idea de un mundo seguro en el que habitar sino un cuerpo extraño, un espacio no-familiar, la casa encantada, lo unheimlich.

\footnotetext{
14 FILLOL, S., op. cit. p. 190.

15 BURCH, N., El tragaluz del infinito, Madrid, Cátedra, 1999, traducción de Francisco Llinas, pp. 194-195.

16 FILLOL, S., op. cit. p. 194.
} 


\section{Bibliografía}

Burch, N., El tragaluz del infinito, Madrid, Cátedra, 1999.

Burch, N., Praxis del cine, Madrid, Fundamentos, traducción de Ramón Font, 2008.

Deleuze, G., Guattari, F., El Anti-Edipo, Capitalismo y esquizofrenia I, Barcelona, Paidós, 1985.

Deleuze, G., Guattari, Félix, Mil mesetas, Capitalismo y esquizofrenia II, Valencia, Pretextos, 2004.

Fillol, S., Manifestaciones de una lejanía (por cercana que pueda estar), Tesis doctoral UPF. (http://hdl.handle.net/10803/31899).

Gorbman, C., Unheard Melodies: Narrative Film Music, Bloomington, Indiana University Press, 1987.

Royle, N., The Uncanny. New York, Routledge, 2003.

Seitz, J., Cinematographic Annual 1930, Nueva York, Arno Press, 1972.

Seldes, G., "The movies commit suicide", en Harper's, Nueva York, noviembre de 1928, p. 710.

Spadoni, R., Uncanny bodies, the coming of sound film and the origins of the horror genre, Berkeley, University of California Press, 2007.

Tsivian, Y., Early Cinema in Russia and Its Cultural Reception, London, Routledge, 1994. 
